\title{
Health-Enabling and Ambient Assistive Technologies: Past, Present, Future
}

\author{
R. Haux', S. Koch', N.H. Lovell ${ }^{3}$, M. Marschollek', N. Nakashima ${ }^{4}$, K.-H. Wolf' \\ 1 Peter L. Reichertz Institute for Medical Informatics, University of Braunschweig - Institute of \\ Technology and Hannover Medical School, Germany \\ 2 Health Informatics Centre, LIME, Karolinska Institutet, Stockholm, Sweden \\ ${ }^{3}$ Graduate School of Biomedical Engineering, UNSW, Sydney, Australia \\ ${ }^{4}$ Medical Information Center, Kyushu University Hospital, Fukuoka, Japan
}

\section{Background and Objectives}

\subsection{Background}

During the last decades, health-enabling and ambient assistive technologies became of considerable relevance for new informatics-based forms of diagnosis, prevention, and therapy. In this context, the editors of the IMIA Yearbook of Medical Informatics assigned an exciting task to us. For its 25 th volume we were asked to "describe the state of the art of health-enabling and ambient assistive technologies in 1992 and today, and its evolution over the last 25 years." The editors "would like to see a discussion where the expectations for the field were in 1992, if they were realized and what particular events occurred that disrupted, derailed, or accelerated the planned development (political, technical, societal, etc.). Another dimension to cover is a projection of where the field is expected to be in the next 25 years." [1].

\subsection{Objectives}

For accomplishing this task we tried to reflect on three questions:

[past ] How did research on health-enabling and ambient assistive technologies evolve during the last 25 years?

[present] Where are health-enabling and ambient assistive technologies today?

\section{Keywords}

Medical informatics, biomedical engineering, health informatics, ambient assisted living, health-enabling technologies.

Yearb Med Inform 2016;Suppl1:S76-91 http://dx.doi.org/10.15265/IYS-2016-s008

Published online June 30, 2016
Yearbook appeared, to 2011 (i.e. not only 1992), as [present] the time from 2012 to 2015 (i.e. not only 2015, the year where this manuscript was written). As [future] we considered the next 25 years, i.e. the time from 2016 to 2041.

The approaches, we selected, to receive answers to the questions for the [past] and the [present] were to report

[pub] on selected publications,

[kpv] on some key projects and visions, and

[lel] on lessons learned

regarding health-enabling and ambient assistive technologies. As suggested by the Yearbook editors, for [ $l e l]$ we tried to consider aspects of information processing methodology and information and communication technology as well as political and societal aspects.

For the question on the [future], the approach, we selected, was to present our views

[next25y] on where the field is expected to be in the next 25 years and [aspects] on which methodological and technological aspects as well as which political and societal aspects should be considered.

\subsection{Limitations}

Readers should be are aware that our answers to [past].[kpv], [past]. [lel], [present]. [kpv], [present]. [lel], [future].[next25y] and [future]. [aspects] are subjectively biased. Even for [past]. [pub] and [present]. [pub], by defining our search strategy, a certain degree of subjectiv- 
ity cannot be avoided. Also, we will mainly focus on research in this field, and less so on practice and education.

\subsection{Structure}

Before presenting our answers to questions [past] in section 4 and [present] in section 5 , with respective sections for [pub], [kpv] and [lel], and to [future] in section 6, with sections for [next25y] and [aspects], we had to define our understanding of the term health-enabling and ambient assistive technologies in section 2. The methods we chose, on how to obtain answers to the three questions with its respective approaches, are presented in section 3 .

\section{What are Health-Enabling and Ambient Assistive Technologies?}

\subsection{What they are}

Health-enabling and ambient assistive technologies are, according to our understanding, ambiently used sensor-based information and communication technologies, aiming at contributing to a person's health and health care as well as to her or his quality of life.

\subsection{Synonymous Terms}

Synonymous or at least very close terms in this context are, in our opinion, the terms ambient assisted living for health care [2], ambient assistive technologies for health care [3], ambient intelligence for health care [4], health-enabling technologies [3], pervasive computing technologies for health care [5], pervasive health [6], pervasive health care [7], smart home technologies for health care [8], and ubiquitous health care (uHealth, [9]).

\subsection{Objectives and Users}

As mentioned in section 2.1, health-enabling and ambient assistive technologies intend to contribute to a person's health and health care as well as to her or his quality of life [10]. Often such persons do or may in the future suffer from functional impairments. These impairments can be related to advanced age [11].

Criteria for contributing to health care may be that these technologies contribute to make care affordable, efficient, and/or of high-quality. Quality of life often includes as a major aspect self-determined and self-sufficient (autonomous) life styles, while informational self-determination and data privacy are preserved. Further, these technologies help to enable social inclusion in spite of impairments as well as a life with dignity.

In supporting new ways of living and new ways of care (Figure 1, from [12], p. 86), health-enabling and ambient assistive technologies intend to support activities of health care and of preventive health [13]. Tools based on these technologies may be used by the respective person herself or himself, by health care professionals (nurses, physicians, ...), and/or by informal care givers (close persons, relatives, ...), who are taking care of this person.

\subsection{Ambience, Sensors and Services}

Ambiently, as mentioned in section 2.1, means that sensors are typically used either

- in persons' living environments such as homes (with room-based sensors, e.g. for motion analysis) or in other daily environments of persons like e.g. cars, workplaces, or shopping centers. Or they are used

- on a person"s body (with body-based sensors, e.g. for acceleration measurement). Such body-based sensors can even be immersive or implanted (e.g. in pace makers or in knee prostheses).

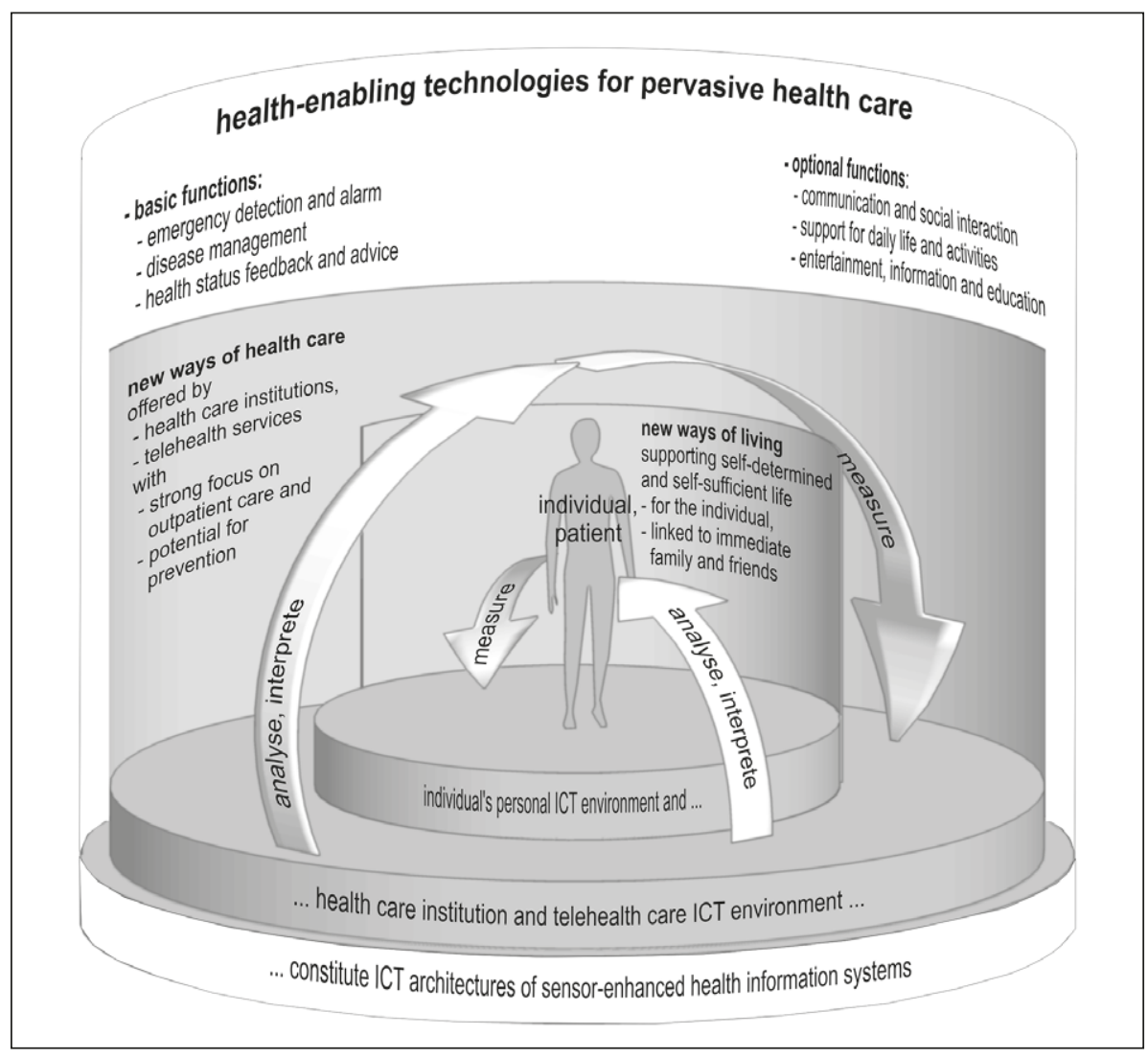

Fig. 1 The double circle: new ways of living and new ways of health care supported by health-enabling and ambient assistive technologies (from [12], p. 86). 
By using sensors a variety of signals can be measured, e.g. acoustic, video, bioelectric (like cardiac signals), optical, pressure, and temperature signals like body temperature $[14,15]$. Most activities of daily living can be recorded using for example door contact switches, motion sensors, power meters, and vibration sensors (e.g. in drawers). Last but not least wearable acceleration sensors and/ or sensors for identifying a person's location (e.g. via GPS) are of importance in this context. Many of these sensors are inexpensive. Sometimes they are already available in existing tools like mobile phones.

Basic services being supported by health-enabling and ambient assistive technologies are

- emergency detection and notification (e.g. for fall detection, $[16,17])$,

- disease management (usually for chronic diseases, e.g. coronary artery disease, and often based on measuring and analyzing activities of daily living) and

- health status feedback and advice (consultation [18]).

These services may be accompanied by supporting non-health related 'social' services like communication and social interaction tools (with peers, close persons, relatives, care givers, ...), and/or general services supporting daily life through education, entertainment, information, and wellness management ([12], pp. 82-83, [19]).

\subsection{Health Information Systems and Electronic Health Records}

Health-enabling and ambient assistive technologies should also be viewed as components of health information systems (HIS), which support health care processes ([20] chapter 4). In HIS terminology these tools are certain computer-based application systems, which are installed on physical subsystems like computer systems and support specific services (as mentioned in section 2.3). Such services are in the context of HIS usually called (enterprise) functions.

As such application systems on the physical layer include sensors, HIS using such tools are called sensor-enhanced HIS $[21,22]$. As for the functions, listed in sec- tion 2.3, usually more than one health care institution is involved and since a person's home is typically also included, such HIS are also denoted as transinstitutional HIS ([20] section $4.3,[22]$ ).

Data from such health-enabling and ambient assistive technology tools and findings based on these data (which may be derived automatically, semi-automatically, or manually) may or perhaps should become part of a person's electronic health record [23]. The applications must be understood as informatics diagnostics and informatics therapeutics tools ([24], p. 606).

\subsection{What They Are not}

Health-enabling and ambient assistive technologies differ

- from ambient assisted living, ambient intelligent, pervasive, ubiquitous and/or smart home technologies (although having been mentioned in section 2.2), if no contribution to a person's health and health care or her or his quality of life is intended;

- from "conventional' information and communication technologies as well as from technologies used in eHealth [25, 26, 27], mHealth [28], telemedicine/ telehealth [29,30], and/or telemonitoring $[31,32]$ where sensors are not used in an ambient way as described in section 2.4;

- from sensor-based tools for wellness management, if these tools are primarily used for lifestyle and sports and if they are not related to health care or to preventive health [28].

Certainly there are grey zones in differentiating health-enabling and ambient assistive technologies from some technologies mentioned above.

\section{Methods}

\subsection{Overview}

To receive answers to the questions stated we chose the methods presented in table 1 . The report on selected publications (in sections 4.1 and 5.1) can be regarded as systematic review according to the PRISMA statement [33].

\subsection{How Publications Were Selected}

\section{Articles Included}

For [pub] all original research articles published in the IMIA Yearbook volumes 1 (in 1992) to 24 (in 2015) were included in our search. These papers had a clear focus on research and were

- either original articles written for a Yearbook volume (e.g. IMIA Yearbook reviews, surveys, but also keynotes, prefaces, working group contributions ${ }^{1}$, as well as IMIA award articles)

- or original articles having been published first elsewhere and having been selected as 'best papers' (and until 2005 also reprinted) in a Yearbook volume.

We excluded articles from our search, if they were assigned as comments, editorials, introductions, obituaries, President's statements, reports about IMIA (and its members, working groups, etc.), reports about Medinfo conferences, synopses, as well as articles in codes of ethics, education ${ }^{2}$, history, in memoriam, and white paper sections.

A list of the included and excluded articles can be obtained upon request to the first author.

\section{Articles Selected}

From the included articles the authors (Table 1) independently selected those manuscripts, which covered health-enabling and ambient assistive technologies as defined in chapter 2 .

To determine if a Yearbook article met the mentioned selection criterion, the content in the Yearbooks was used, which mostly (but not always) were the articles' full texts. IMIA Yearbooks are available in print for the years 1992 to 2013 and in electronic form since $2006^{3}$.

For selected manuscripts each of the respective authors wrote a brief summary. In case that an article had been selected by

\footnotetext{
if they were published as original articles, i.e. since IMIA Yearbook 2011

2 usually two sections per Yearbook, with varying names such as education, computer-supported education, education and consumer (health) informatics, education and training, and research and education

3 at http://www.schattauer.de/en/magazine/ subject-areas/journals-a-z/imia-yearbook, last access: November 28, 2015
} 
Table 1 Methods chosen (with time frames and responsible authors) to answer the three questions raised and presented with their respective approaches and references to the sections, where results are presented. Abbreviations were introduced in section 1.

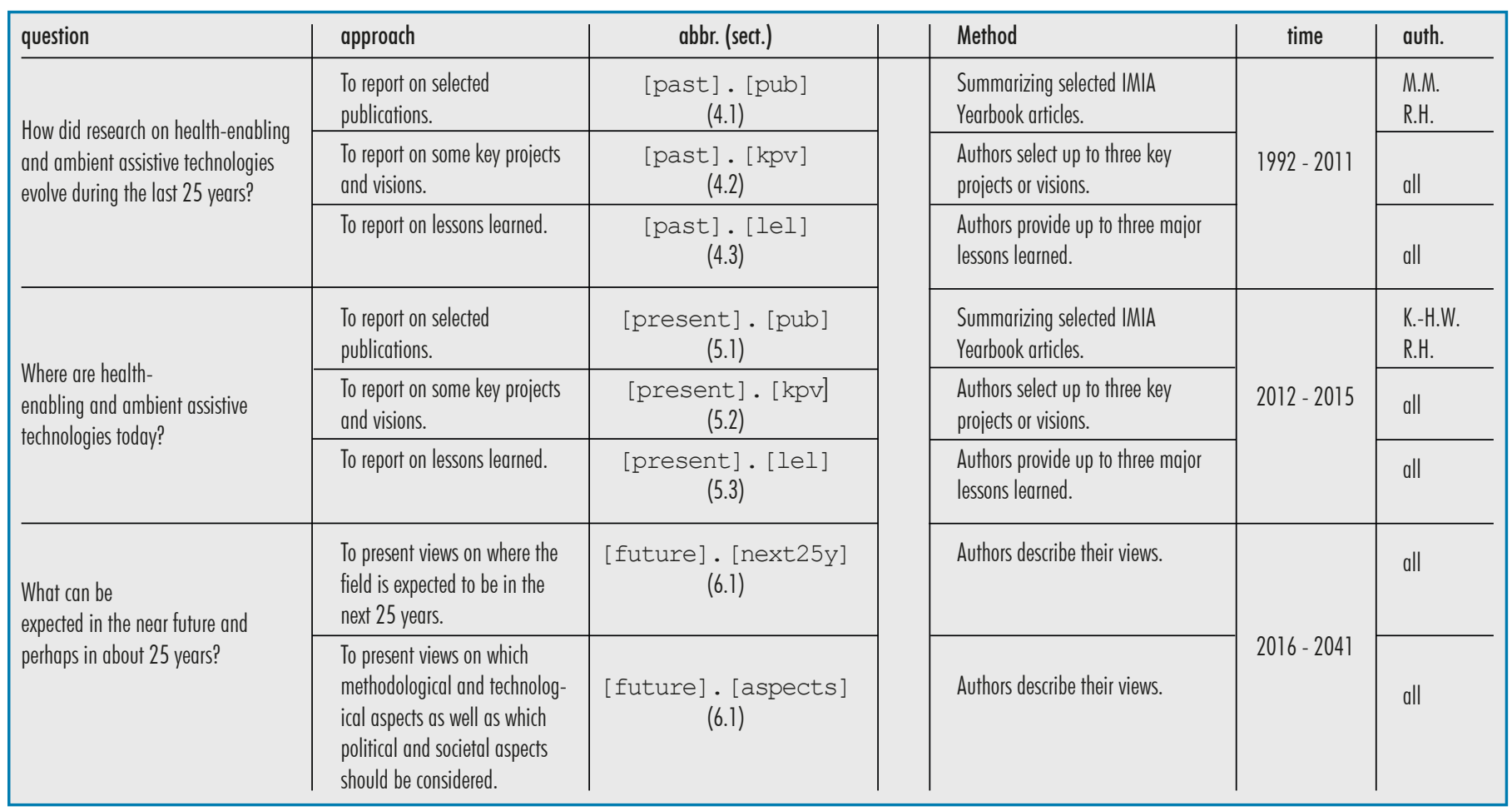

both authors, it was included in the set of selected articles, and the two summaries were merged and edited.

In case that only one author selected an article, the authors reached consensus on whether the article should be selected or not. If yes, the available summary was either used as written or edited.

\subsection{How Key Projects, Visions, Lessons Learned, and Expectations on Future Aspects Were Compiled}

For $[\mathrm{kpv}]$ all authors were independently asked:

"Please select up to three key projects and/or visions (with references) regarding health-enabling and ambient assistive technologies

[past] in the time from 1992 to 2011 and

[present] in the time from 2012 to 2015 and please report briefly why these projects or visions had been of importance. Key projects and visions can be by other persons (research groups, ...) or by you (e.g. on projects where you were/are part of the respective research group)."

For [ lel] all authors were independently asked:

"Please list up to three lessons you learned regarding health-enabling and ambient assistive technologies

[past] in the time from 1992 to 2011 and

[present] in the time from 2012 to 2015.

Please consider aspects of information processing methodology and information and communication technology as well as political and societal aspects."

For [next25y] all authors were independently asked:
"Please describe briefly the anticipated changes to the field of health-enabling and ambient assistive technologies in the next 25 years, i.e. in the time from 2016 to 2041."

For [aspects] all authors were independently asked:

"Please describe briefly which methodological and technological aspects as well as which political and societal aspects should be considered in the next 25 years, i.e. in the time from 2016 to 2041."

After receiving the answers, the first author combined all results and edited them. As the answers varied in length, most were too long to be presented in detail and were shortened. Frequently, a presented topic was mentioned by more than one of the authors. Also, closely related topics were combined. For all texts presented here, approval was given by all authors. 


\section{Health-Enabling and Ambient Assistive Technologies: The Past}

\subsection{Selected Publications}

Table 2 contains the selected articles on health-enabling and ambient assistive technologies. Please note that the term review in table 2 has been used in a very broad sense. Originally, we wanted to select only papers, whose major content was health-enabling and ambient assistive technologies. We discovered, however, that while many papers clearly touched this field, the field was not the major content. We finally decided to include only papers with major content in health-enabling and ambient assistive technologies.

Papers containing statements on health-enabling and ambient assistive technologies are published rather late with the first year being 2002, in the Yearbook's 10th volume. From 2005 onwards, in nearly each Yearbook volume, papers with this content could be found. These papers however form a minor part of published research articles in medical informatics (20 out of 320 articles between 2005 and 2011 , i.e. about $6 \%$ ).

Before 2002, there were several Yearbook publications on telemedicine which we did not to include according to our definitions. Perspective papers on visions using these technologies form a considerable part of the selected publications (5 articles of 20). Included papers were spread over various sections of the IMIA Yearbooks.

\subsection{Some Key Projects and Visions}

The authors were significantly influenced by research groups led by (in alphabetic order) George Demiris (USA), Paul Lukowicz (Germany), Dimitar Stefanov (Bulgaria), and Gerhard Tröster (Switzerland). Some of their papers were already mentioned in section 4.1. Other methodical papers and project reports which authors identified as seminal to their own research were $[66,67$, $68,69,70,71,72,73,74]$.
One of the first demonstrations of health-enabling and ambient assistive technologies was reported in [75]. A multidisciplinary research project with associated field trials in New South Wales, Australia used ambient sensing technologies configured to record occupancy and utilization of resources of older persons living at home alone. It was a decade before wireless technology was routinely being used for similar measurements.

Other key projects identified by the authors included PlaceLab (MIT, [76, 77]), INCA (EU, [78]), the Veterans Health Administration US home telehealth program [79], HealthDesign (a US national program, [80]), and GAL (Lower Saxony, Germany [81]), FitForAge (Bavaria, Germany [82]), and OASIS (EU, [83]).

PlaceLab was an apartment that was equipped with a wide range of sensors. It was one of the first installations to observe people living under realistic conditions in an environment totally controlled and observed by researchers. The INCA project aimed at improving diabetes therapy by creating a personal closed-loop system interacting with a telemedical remote control. It was among the first projects including two loops, one direct patient to patient loop and one with the medical professional in the extended telemedical loop. Between 2003 and 2007, the Veterans Health Administration's 'Care Coordination/Home Telehealth' program intended to coordinate the care of veteran patients with chronic conditions and to avoid their unnecessary admission to long-term institutional care. The GAL network researched from 2008 on the topic of design of environments for aging from a variety of perspectives. Researchers from many different disciplines shared their visions, concerns, and perspectives, and applied the theoretical results by developing use cases that they implemented and tested in real life. FitForAge concentrated on supporting mobility and life at home and in work environments as application scenarios, with cross-sectional topics on systems development and products and services. OASIS focused on developing ICT architectures for products and services in ageing societies.

\subsection{Lessons Learned?}

We concluded that testing and understanding technology was a major issue during this phase. In the beginning health-enabling and ambient assistive technologies were expensive and with limited performance and stability. Much of the development was technologically driven. So developments were often not based on clinical needs or the needs of patients. Measuring activities and vital signs with body-based or room-based sensors and understanding the meaning of the data measured in the context of diagnosis, therapy, prevention, and safe living were of importance.

There was also a gap between the visions presented and the reality of using such technologies. Fall detection and fall prevention was a priority area of research. New disease management opportunities became available through this technology as individuals worked with their health care providers to learn to manage their own diseases. However, studying disease or falls in the frail elderly was hugely expensive because of the complex co-morbidities (and thus heterogeneous patient cohorts) and the fact that disease progression can often be slow. Thus randomized clinical trials aiming to demonstrate improved patient health outcomes must be conducted for many years leading to many reports in the literature of pilot studies that frequently did not reach statistical significance.

In addition to being able to use and control these new and promising technologies, it became clear that care process change had to be considered, e.g., by adapting standards (e.g. communication standards) and even laws. For communication standards, the eHealth resolution of the World Health Assembly was important ([84], see also [85]), however progress was slow. Progress in adapting laws was even more disappointing. Introducing reimbursement for these new care processes was very limited and became another factor slowing progress.

Unfortunately, educational programs in biomedical and health informatics seldom considered these technologies in their programs. This prevented progress in improvement of health care processes and of our understanding how data from such technologies should be analyzed and become part of a person's health record. 
Table 2 IMIA Yearbook articles in volumes / years 1992 to 2011 with a major content on health-enabling and ambient assistive technologies. Articles are referenced, briefly described and characterized by article type articles containing primarily specific research (sres, e.g. presenting a study and/or methodology / technology), a review (rev), or perspectives (psp). We also included the yearbook section name, n(i): number of articles included, and $n(s)$ number of articles selected per year.

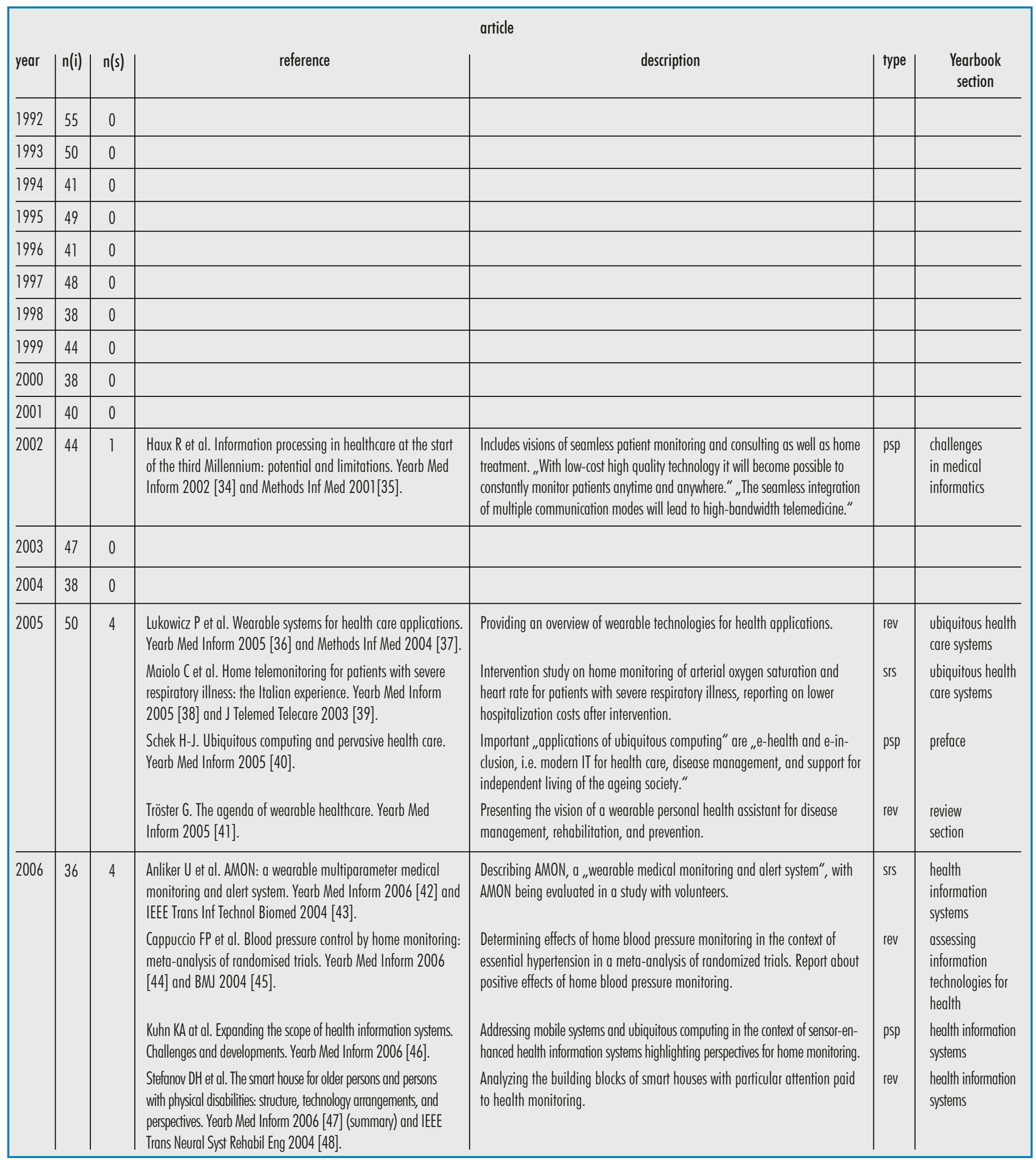


Haux et al.

Table 2 (continued) IMIA Yearbook articles in volumes / years 1992 to 2011 with a major content on health-enabling and ambient assistive technologies. Articles are referenced, briefly described and characterized by article type - articles containing primarily specific research (sres, e.g. presenting a study and/or methodology / technology), a review (rev), or perspectives (psp). We also included the yearbook section name, n(i): number of articles included, and $n(s)$ number of articles selected per year.

\begin{tabular}{|c|c|c|c|c|c|c|}
\hline & & & & article & & \\
\hline year & n(i) & $\mathrm{n}(\mathrm{s})$ & reference & description & type & $\begin{array}{l}\text { Yearbook } \\
\text { section }\end{array}$ \\
\hline 2007 & 43 & 4 & $\begin{array}{l}\text { Istrate D et al. Information extraction from sound for medical } \\
\text { telemonitoring. Yearb Med Inform } 2007 \text { [49] and IEEE Trans } \\
\text { Inf Technol Biomed } 2006 \text { [50]. }\end{array}$ & $\begin{array}{l}\text { Sound surveillance system in the context of home care. ",The originality of this re- } \\
\text { search is to use sound as an informative source simultaneously with other sensors." }\end{array}$ & sIS & $\begin{array}{l}\text { sensor, signal and } \\
\text { imaging informatics }\end{array}$ \\
\hline & & & $\begin{array}{l}\text { Konstantas D. An overview of wearable and implantable } \\
\text { medical sensors. Yearb Med Inform } 2007 \text { [51]. }\end{array}$ & $\begin{array}{l}\text { Overview on wearable and implantable sensors and actuators for health care } \\
\text { including home care. }\end{array}$ & rev & $\begin{array}{l}\text { sensor, signal and } \\
\text { imaging informatics }\end{array}$ \\
\hline & & & $\begin{array}{l}\text { Pärkkä J et al. Activity classification using realistic data from } \\
\text { wearable sensors. Yearb Med Inform } 2007 \text { [52] and IEEE Trans } \\
\text { Inf Technol Biomed } 2006 \text { [53]. }\end{array}$ & $\begin{array}{l}\text { Use of wearable sensors for improving awareness of daily activities in the } \\
\text { context of healthy lifestyles. }\end{array}$ & SIS & $\begin{array}{l}\text { sensor, signal and } \\
\text { imaging informatics }\end{array}$ \\
\hline & & & $\begin{array}{l}\text { Shea S et al. A randomized trial comparing telemedicine case } \\
\text { management with usual care in older, ethnically diverse, } \\
\text { medically underserved patients with diabetes mellitus. Yearb } \\
\text { Med Inform } 2007 \text { [54] and I Am Med Inform Assoc } 2006 \text { [55]. }\end{array}$ & $\begin{array}{l}\text { Randomized trial on patients with diabetes mellitus. Intervention group with } \\
\text { remote monitoring of glucose and blood pressure with electronic upload to } \\
\text { electronic patient records resulting in improved case management. }\end{array}$ & sis & $\begin{array}{l}\text { health } \\
\text { and dinical } \\
\text { management }\end{array}$ \\
\hline 2008 & 40 & 3 & $\begin{array}{l}\text { Demiris G et al. Technologies for an aging society: a systematic } \\
\text { review of „smart home” applications. Yearb Med Inform } 2008 \text { [56]. }\end{array}$ & $\begin{array}{l}\text { Review of smart home technology projects and their functionalities. Authors } \\
\text { comment that evidence for the impact on clinical outcomes is lacking. }\end{array}$ & rev & $\begin{array}{l}\text { human } \\
\text { factors }\end{array}$ \\
\hline & & & $\begin{array}{l}\text { Logan AG et al. Mobile phone-based remote patient monitoring } \\
\text { system for management of hypertension in diabetic patients. } \\
\text { Yearb Med Inform } 2008 \text { [57] and Am J Hypertens } 2007 \text { [58]. }\end{array}$ & $\begin{array}{l}\text { Blood-pressure monitoring system for remote hypertension monitoring of } \\
\text { diabetic patients. }\end{array}$ & sis & $\begin{array}{l}\text { health } \\
\text { and dinical } \\
\text { management }\end{array}$ \\
\hline & & & $\begin{array}{l}\text { Zheng JW et al. A wearable mobihealth care system supporting } \\
\text { real-time diagnosis and alarm. Yearb Med Inform } 2008 \text { [59] } \\
\text { and Med Biol Eng Comput } 2007 \text { [60]. }\end{array}$ & $\begin{array}{l}\text { Long-term monitoring of vital signs for high-risk cardiovascular patients } \\
\text { through wearable shirts, } \mathrm{EGG} \text {, respiration, and activity measurement. }\end{array}$ & sIS & $\begin{array}{l}\text { sensor, signal and } \\
\text { imaging informatics }\end{array}$ \\
\hline 2009 & 54 & 1 & $\begin{array}{l}\text { 0'Shea Sl et al. Direct-to-patient expert system and home INR } \\
\text { monitoring improves control of oral anticoagulation. Yearb Med } \\
\text { Inform } 2010 \text { [61] and J Thromb Thrombolysis } 2008 \text { [62]. }\end{array}$ & $\begin{array}{l}\text { Intervention study on Internet-supervised patient self-management of oral } \\
\text { anticoagulant therapy through prothrombin time monitoring at home. } \\
\text { Positive outcomes for internet-supervised patient self-management. }\end{array}$ & sis & $\begin{array}{l}\text { health } \\
\text { and dinical } \\
\text { management }\end{array}$ \\
\hline 2010 & 42 & - & & & & \\
\hline 2011 & 55 & 3 & $\begin{array}{l}\text { Demiris } G \text { et al. Smart homes and ambient assisted living appli- } \\
\text { cations: from datat to knowledge-empowering or overwhelming } \\
\text { older adults? Yearb Med Inform } 2011 \text { [63]. }\end{array}$ & $\begin{array}{l}\text { Highlighting how smart home and ambient assisted living systems utilize } \\
\text { ubiquitous technologies including sensors. }\end{array}$ & psp & $\begin{array}{l}\text { human factors and } \\
\text { organizational } \\
\text { issues }\end{array}$ \\
\hline & & & $\begin{array}{l}\text { Maeder AJ et al. Next generation telehealth. Yearb Med Inform } \\
2011 \text { [64]. }\end{array}$ & $\begin{array}{l}\text { Includes visions of ubiquitous connectivity and of self-care tools for ,stim- } \\
\text { ulating individuals to adopt and maintain a healthy ... lifestyle, enhanced } \\
\text { by health sensor monitoring, interpretataion of sensor data, visualization of } \\
\text { health-related data, and providing individual custom health care guidance." }\end{array}$ & psp & $\begin{array}{l}\text { towards health } \\
\text { informatics } 3.0\end{array}$ \\
\hline & & & $\begin{array}{l}\text { Stroetmann V et al. Understanding the role of device level } \\
\text { interoperability in promoting health - lessons learned from the } \\
\text { SmartPersonalHealth Project. Yearb Med Inform } 2011 \text { [65] }\end{array}$ & $\begin{array}{l}\text { Report on lessons learned from the, SmartPersonallHome' project, highlight- } \\
\text { ing the necessity of interoperability. }\end{array}$ & sis & $\begin{array}{l}\text { sensor, signal and } \\
\text { imaging informatics }\end{array}$ \\
\hline
\end{tabular}




\section{Health-Enabling and Ambient Assistive Technologies: The Present}

\subsection{Selected Publications}

Table 3 contains the selected articles with major content on health-enabling and ambient assistive technologies. The comments of section 4.1's first paragraph apply also for this section.

Health-enabling and ambient assistive technologies are still not in the center of medical informatics research, although papers with major content could be found rather continuously (in 3 of the 4 issues). 18 out of 231 articles (about 8\% of the Yearbooks papers) addressed health-enabling and ambient assistive technologies as major content.

More and more publications assumed that a person's home is an important component in health care. There seems to be a trend that the home, with sensor systems specifically (and maybe temporarily) being used for health care, is becoming a new important area or space for diagnosis and therapy. As such the home would complement specialized health care 'areas' for inpatient and outpatient care such as hospitals, clinics, and general practices.

\subsection{Some Key Projects and Visions}

In the present, authors observed a shift to self-tracking of persons in the context of prevention and health care (but not exclusively). Studies about self-tracking behavior of patients with chronic diseases can be found in [108] and from quantified self-movement in [109] (see also the respective papers in 5.1). Technology is now much easier to use. The significant use of social media, smart phones, and accessories such as fitness trackers, smart watches, and digital appliances in the home environment paves the way for its exploitation in health care.

It is now possible to monitor aging patients, who live alone, around the clock using such technologies. In the context of new ways for health care, the Whole System Demonstrator project was discussed as a key project of significant importance to the authors (WSD, e.g. [110]) as well as the GAL-NATARS study ([111], see also [112]).

The WSD project reported that for recruited patients with diabetes, chronic obstructive pulmonary disease, or heart failure the 12 month mortality rate was lower for intervention patients receiving telehealth services including health-enabling technologies than for patients in the control group (4.6\% versus $8.3 \%$ ). The GAL-NATARS study showed that health-enabling and ambient assistive technologies can become an important future component for home rehabilitation of geriatric fracture patients.

Other key projects discussed were cohort studies like the German National Cohort [113] and the UK Biobank Cohort [114], both with considerable amount of measured sensor data of persons included as well as the BASIS (Building Automation by a Scalable \& Intelligent System) project which is exploring new ways of energy efficiency and safety for systems based on health-enabling and ambient assistive technologies [115]. The last aspect will be of growing relevance as such systems may have to be regarded as medical devices.

Further, authors commented on the global relevance of health-enabling and ambient assistive technologies, i.e. not only for developed but also for developing countries and mentioned the 'Portable Health Clinic' project for unreached people in Bangladesh $[116,117,118])$. There, a check-up health service has been provided by a sensor package combined with telemedicine for at-risk groups in villages and factories (total 16,741 subjects) in Bangladesh from 2012 on. The study suggests that this may be a cost-effective health check-up service based on their data mining analyses.

\subsection{Lessons Learned?}

We discuss in the section the lessons learned in regards to orientation in research and practice, methodology, technology, health care process integration, and ethics.

Today patients are becoming the main drivers in the collection of sensor data (quantified self-movement). Health-enabling and ambient assistive technologies are still mainly considered to support health care processes rather being recognized for the impact they have on self-care processes as well. There is demand from the health care side, especially from clinical research, to collect patient data, but feedback mechanisms are often lacking. In addition to persons/patients and health care institutions/health care professionals, this technology creates a need to collaborate with other institutions, who are supporting the daily life of persons, e.g. with housing companies. Finally, further impact studies for diagnostic relevance and therapeutic efficacy are still missing, although today's technology seems to be now mature enough to conduct such studies. The need for large sample sizes has already been discussed in section 4.3. Exploring relevance and efficacy will, however, be crucial for progress in understanding and applying health-enabling and ambient assistive technologies.

It is now possible to monitor aging patients, who live alone, around the clock by sensor networks. However, raw sensor data without any processing would exhaust physicians or medical staff. The lack of real world data to serve as examples is hindering the development of new methods to integrate data. Analysis techniques are still in their infancy. In the analysis of sensor data for ambulation and falls we learnt that many research groups worldwide fell into analysis and methodological traps that limit the generalizability and usefulness of some of the analyses and models reported in the literature. Some of the associated issues and lessons learnt are summarized in [119] and include overly-optimistic results in light of small sample sizes, questionable modelling decisions, and problematic validation methodologies. With the enormous increase in availability of rich sensor data and many possible analytical approaches, researchers are provided with the intellectual and creative freedom to explore datasets without constraints. However this new freedom must be treated with caution if we desire to create generalizable prognostic tools of any clinical value. Finally, research in more traditional fields like biosignal analysis and interpretation is now also including research on health-enabling and ambient assistive technologies, e.g. 
Haux et al.

Table 3 IMIA Yearbook articles in volumes / years 2011 to 2015 with major content on health-enabling and ambient assistive technologies. Articles are referenced, briefly described and characterized by article type articles containing primarily specific research (sres, e.g. presenting a study and/or methodology / technology), a review (rev), or perspectives (psp). We also included the yearbook section name, n(i): number of articles included, and $n(s)$ number of articles selected per year.

\begin{tabular}{|c|c|c|c|c|c|c|}
\hline year & $n(i)$ & $n(s)$ & reference & description & type & $\begin{array}{c}\text { Yearbook } \\
\text { section }\end{array}$ \\
\hline 2012 & 54 & 7 & $\begin{array}{l}\text { Demiris G et al. Mobilizing Older Adults: Harnessing the } \\
\text { Potential of Smart Home Technologies. Contribution of the IMIA } \\
\text { Working Group on Smart Homes and Ambient Assisted Living. } \\
\text { Yearb Med Inform } 2012 \text { [86]. } \\
\text { Gogia SB et al. Using Personal Handheld Computing Devices for } \\
\text { Personalizing Healthcare. Yearb Med Inform } 2012 \text { [87]. } \\
\text { Khushaba RN et al. Driver drowsiness classification using fuzzy } \\
\text { wavelet-packet-based feature-extraction algorithm. Yearb Med } \\
\text { Inform } 2012 \text { [88] and IEEE Trans Biomed Eng } 2011 \text { [89]. } \\
\text { Koch S et al. Critical advances in bridging personal health infor- } \\
\text { matics and clinical informatics. Yearb Med Inform } 2012 \text { [90]. } \\
\text { Leong TY. Toward patient-centered, personalized and personal } \\
\text { decision support and knowledge management: a survey. Yearb } \\
\text { Med Inform } 2012 \text { [91]. } \\
\text { Paton C et al. Self-Tracking, Social Media and Personal Health } \\
\text { Records for Patient Empowered Self-Care. Yearb Med Inform } \\
2012 \text { [92]. } \\
\text { Wac K. Smartphone as a personal, pervasive health } \\
\text { informatics services platform: literature review. Yearb Med } \\
\text { Inform } 2012 \text { [93]. }\end{array}$ & $\begin{array}{l}\text { Highlighting "the potential of smart home applications to for older adults", } \\
\text { with an emphasis on also providing opportunities for tailored interventions. } \\
\text { A "theoretical framework for assessing mobility parameters and utilizing this } \\
\text { information to enable behavior change" is presented and discussed. } \\
\text { Exploring "the current status of personal handheld computing devices for } \\
\text { personalizing healthcare", discussing that such "devices can be used to } \\
\text { collect measurements and observations (e.g. motion, vital signs)". } \\
\text { Extracting and classifying driver drowsiness-related information from EEG, } \\
\text { electrooculogram (EOG), and ECG signals. } \\
\text { Investigating publications on the intersection of personal health and clinical in- } \\
\text { formatics, discussing "sensor-based health-enabling technologies" and personal } \\
\text { health systems and services "relying on the adoption of medical sensors". } \\
\text { Highlighting "the challenges and opportunities in decision support and } \\
\text { knowledge management for patient-centered, personalized, and personal } \\
\text { health care" including monitoring devices at home. } \\
\text { Investigating the use of "self-tracking technologies in the health sector". } \\
\text { The use of "self-tracking tools, particularly in the health and fitness sector, } \\
\text { but also used in the management of chronic diseases" appears to increase. } \\
\text { However, evidence "of efficacy and effectiveness is limited to date". } \\
\text { Exploring "current trends of mobile computing and communications } \\
\text { technologies enclosed in a smartphone" enabling "the provision of personal, } \\
\text { pervasive health informatics services". }\end{array}$ & rev & $\begin{array}{l}\text { sensor, signal } \\
\text { and imaging } \\
\text { informatics } \\
\text { health } \\
\text { information } \\
\text { systems } \\
\text { sensor, signal } \\
\text { and imaging } \\
\text { informatics } \\
\text { human factors and } \\
\text { organizational } \\
\text { issues } \\
\text { decision } \\
\text { support } \\
\text { personal health } \\
\text { and consumer } \\
\text { informatics } \\
\text { sensor, signal } \\
\text { and imaging } \\
\text { informatics }\end{array}$ \\
\hline 2013 & 61 & 4 & $\begin{array}{l}\text { Abbott PA et al. A scoping review of telehealth. Yearb Med } \\
\text { Inform } 2013 \text { [94]. } \\
\text { Jeong S et al. An integrated healthcare system for personalized } \\
\text { chronic disease care in home-hospital environments. Yearb } \\
\text { Med Inform } 2013 \text { [95] and IEEE Trans Inf Technol Biomed } \\
2012 \text { [96]. } \\
\text { Klasnja P et al. Healthcare in the pocket: mapping the space } \\
\text { of mobile-phone health interventions. Yearb Med Inform } 2013 \\
\text { [97] and J Biomed Inform } 2012 \text { [98]. } \\
\text { McCoy AB et al. State of the art in clinical informatics: evidence } \\
\text { and examples. Yearb Med Inform } 2013 \text { [99]. }\end{array}$ & $\begin{array}{l}\text { Reviewing telehealth literature for providing "a snapshot of some of the cur- } \\
\text { rent developments in the field", referring to the "impact of data originating } \\
\text { from ... sensing technology". } \\
\text { Proposing a "patient status classification method for effectively identifying } \\
\text { and classifying chronic diseases" in the context of joint "at-hospital and } \\
\text { at-home" health care processes including the use of sensors. } \\
\text { Identifying strategies "that have been used in mobile-phone health } \\
\text { interventions" in health care processes. } \\
\text { Presenting recent evidence on clinical informatics in the US, also addressing, } \\
\text { among others, mobile phones, which "can be used as sensory tools". }\end{array}$ & SIS & $\begin{array}{l}\text { health } \\
\text { and clinical } \\
\text { management } \\
\text { health } \\
\text { and clinical } \\
\text { management } \\
\text { health } \\
\text { and clinical } \\
\text { management } \\
\text { evidence-based } \\
\text { health informatics }\end{array}$ \\
\hline 2014 & 56 & 7 & $\begin{array}{l}\text { Capozzi D et al. A generic telemedicine infrastructure for } \\
\text { monitoring an artificial pancreas trial. Yearb Med Inform } 2014 \\
\text { [100] and Comput Methods Programs Biomed } 2013 \text { [101]. } \\
\text { Carrault G et al. Are electronic cardiac devices still evolving? } \\
\text { Yearb Med Inform } 2014 \text { [102]. } \\
\text { Hansen MM et al. Big Data in Science and Healthcare: A } \\
\text { Review of Recent Literature and Perspectives. Yearb Med Inform } \\
2014 \text { [103]. }\end{array}$ & $\begin{array}{l}\text { Example for homes, becoming a place for health care, which has formerly } \\
\text { taken place in hospitals. "Combining ... wireless scales and blood pressure } \\
\text { monitors with a mobile phone we were able to implement a home care } \\
\text { platform providing automatic data acquisition for monitoring patients under- } \\
\text { going peritoneal dialysis". } \\
\text { Reviewing "some important issues occurring during the past year in } \\
\text { implantable devices" including new opportunities for home monitoring. } \\
\text { Addressing the use of sensors in personal environments in the context of } \\
\text { quantified-self activities. }\end{array}$ & rev & $\begin{array}{l}\text { health } \\
\text { and clinical } \\
\text { management } \\
\text { health } \\
\text { information } \\
\text { systems } \\
\text { big data - smart } \\
\text { health strategies }\end{array}$ \\
\hline
\end{tabular}


Table 3 (contiunued) IMIA Yearbook articles in volumes / years 2011 to 2015 with major content on health-enabling and ambient assistive technologies. Articles are referenced, briefly described and characterized by article type - articles containing primarily specific research (sres, e.g. presenting a study and/or methodology / technology), a review (rev), or perspectives (psp). We also included the yearbook section name, n(i): number of articles included, and $n(s)$ number of articles selected per year.

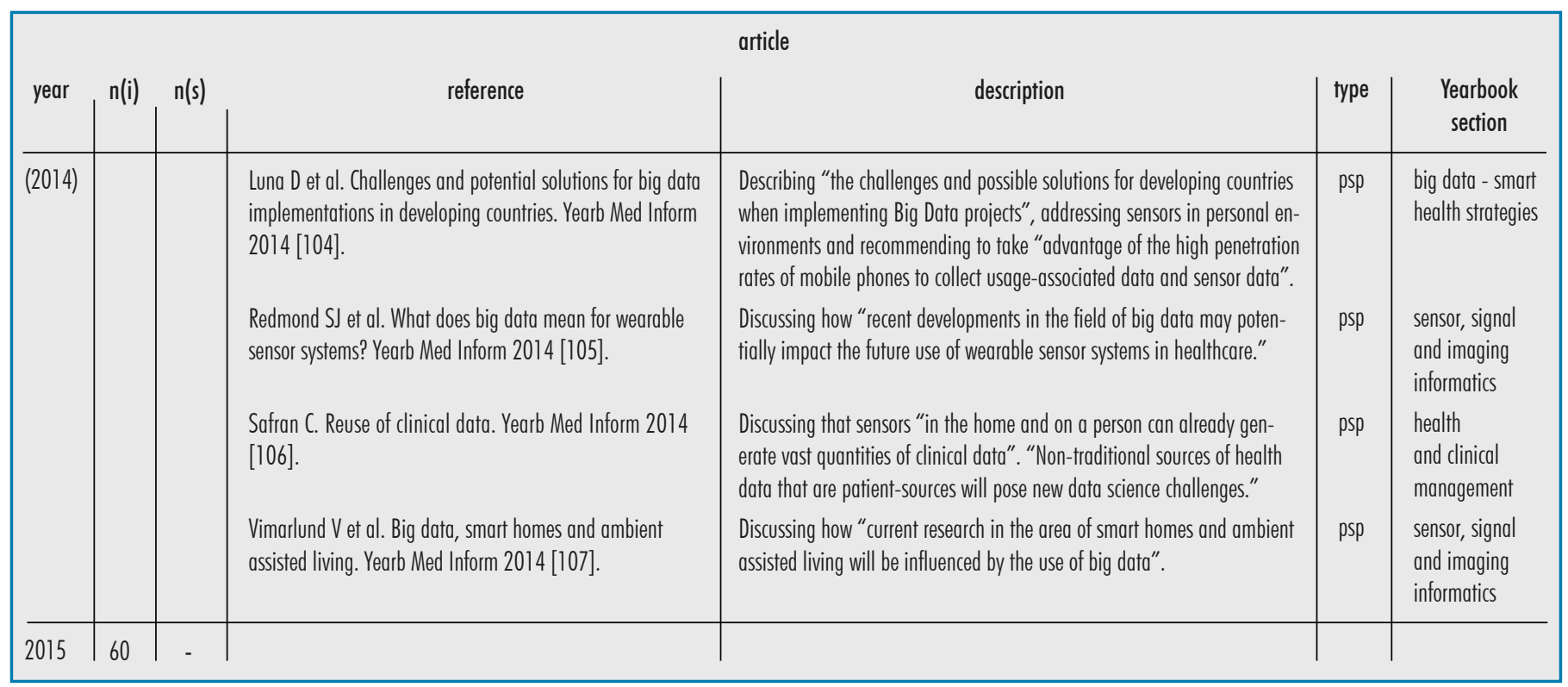

[120] on assessing depressive states, [121] on detecting sleep apnea, and [122] on the use of bed sensors for heart rate monitoring in a recent focus theme of Methods of Information in Medicine.

Nowadays, the emergence of low-cost ubiquitous and energy-efficient wireless technologies [123] and accepted industry standards created wide appeal for wearable sensors to be used for monitoring human movement and for detecting and preventing falls (see [124] for a review). Similar technologies are also having a wide impact in the health informatics area in general (see [125] for a review). From an ambient assistive technology viewpoint, wireless technologies have been a significant enabler as they simplify installation and retrofitting of technologies into living spaces.

For health care process integration, technical means have to be developed to integrate data with classical health data in electronic health records to allow easy access and interpretation by health care professionals. Most of the information gathered resides in isolated silos. Integration of patient data from various sources (e.g. from hospitals and sensor data from a patient's home) into a coherent data repository is also a challenge to be solved (see e.g. [126, 127, 128, 129]). While silos in this context could be seen positively from a data security aspect, they often just hinder the use of the information for the benefit of its producer. Linked data between two or more sensor devices will probably create new useful information. For example, in Japan in the 1990's, diabetic patients could upload self-monitored blood sugar data via the Internet and browse data represented by graphs using the concept of 'information medicine'. However, this service was eliminated after several years because the additional value created by a single kind of data in graph form, may not be efficient enough to sustain the service. Finally, reimbursement for data analysis from health-enabling and ambient assistive technologies and liability issues for physicians treating patients based on such data are still not solved sufficiently.

A broad ethical discussion about who owns the data, who is allowed to process it under which constraints, and what should be done with the results is needed. The relevance of ethical, legal, and social implica- tions (ELSI) of health-enabling and ambient assistive technologies is now recognized (e.g. [112]) and needs further attention.

\section{Health-Enabling and Ambient Assistive Technologies: The Future}

\subsection{Where is the Field Expected to be in the Next 25 Years?}

We highlighted different aspects of the future development of health-enabling and ambient assistive technologies. One author was already involved in predictions at the turn of the century [130] and re-examining these prognoses a few years ago $[131,132]$. Based on these experiences we agreed that there are limitations to such prognoses and their constraints should be taken into consideration for the list of statements in this section. The following statements are somewhat unstructured, but we felt that this listing is probably the best way of presenting the statements. 
In 25 years from now health-enabling and ambient assistive technologies will not even be recognized as such. They will be an integrated part of the health system. These technologies will only form parts of the "big picture' and need to be integrated with other types of data or services such as a genetics-enhanced electronic health records and personals health records. There will be different scenarios of use:

- health-enabling and ambient assistive technologies will be used for population screening;

- patients with chronic diseases use them continuously to track their health or temporarily to achieve a specific aim, e.g. adjustment of medication;

- measurements from these technologies form part of the patient reported outcome measures (PROMs) and patient reported experience measures (PREMs).

Health-enabling and ambient assistive technologies will become more 'ambient' still and will be accepted for specific tasks such as chronic disease monitoring. Insurance companies will adopt this idea if sound studies show potential cost cuts.

Sensors will become capable of measuring medically relevant parameters unobtrusively and non-invasively (blood glucose for example).

Epidemiological studies will change because of new measurement methods of 'exposome' data through health-enabling and ambient assistive technologies (data from a person's environment, her/his activities especially in terms of 'behavior').

Potentially a countermovement of nonadopters of sensor technology could develop with individuals objecting to measuring every detail in life and raising awareness of unfavorable behavior ('prevention dilemma' and conscious disregard of the right thing to do).

Unobtrusive and wearable sensor data are of little value unless they can be interpreted and the potentially big data sets collected can be transformed into knowledge bases. Validated clinical decision support systems that may be used to infer changes in health status appropriate for ambient assisted living data will be developed.

Such developments should align with the progress in developing personalized models of a patient's health - driven to a large extent by the progress in projects related to the virtual physiological human and the physiome, which allow the integration of complex computational models spanning many temporal spatial and temporal scales. Thus the link between genome, to proteome, to cell and organ specific in an individually customisable fashion will be achievable. Health-enabling and ambient assistive technologies will allow this personalized medicine to be measured, delivered, and managed at the point-of-care, potentially within the patient's home environment.

The wireless sensing technologies used for this management will likely diverge into two categories. The first will be pervasive and unobtrusive devices that monitor persons and their interaction with their environment with no direct connection to the individual, thus eliminating many issues relating to compliance in taking measurements or attaching and wearing sensors. One example of this technology approach includes contactless biomotion measurement using radiofrequency sensing to assess sleep-disordered breathing [133]. Other technologies using automated video recognition and terahertz imaging will extend the range of unobtrusive sensing. The second category of sensing will be embedded into implantable devices, which may be purpose-implanted for example to monitor physiological function or gait, or be integrated into an existing device to extend its functionality. One example is the inclusion of triaxial accelerometry devices into a number of regulatory approved medical devices such as spinal cord pain nerve stimulators and implantable heart pumps. Such sensors could easily be used for detecting falls in future generations of these technologies.

In place of hospitals, home care should be the main site of nursing care for elders and disease/health care management worldwide. To avoid a decrease in the quality of service, sensors devices are expected to monitor patients/elders around the clock, more effectively than the nursing staff at a hospital. The keywords are cheap, reliable, and user-friendly for these devices. Processing data from these devices and delivering feedback for the home care site will avoid sending of raw data without any direct processing to physicians/hospitals.

The main beneficiary of these advancements seems to be the wealthy population in developed countries. However, we should in future focus health-enabling and ambient assistive technologies also on poorer populations, even in developing countries. Methodologies that can provide services by database service, as a disease/health care management to poor populations worldwide, should consider the overall cost-effectiveness.

Technology will become more mature. It will be possible to "just use" off-the-shelf technology that is already used by people (future patients as well as health care professionals). This will allow for easier adoption of such new technologies.

In the future, more houses will be equipped with intelligent systems for lighting, heating, and security. In-house entertainment equipment (Surround sound, video, SmartTV) will be ubiquitous and integrated via networks. Wearable or mobile equipment will be common place as well. Utilizing those for the health benefit of the inhabitants is one aspect of the field.

We anticipate difficulties in integrating data for the health benefit of the users. There is a need for interoperability standards, which hopefully will emerge. Furthermore, a concept for the safe and secure handling of data is needed and must be developed. Otherwise, these data will become available to people, who will not act in the best interest of the person (e.g. shared on social media or distributed by similar means).

Like any new technology, health-enabling and ambient assistive technologies will see emergence and decline of particular formats and technologies until specific standards emerge (Similar to VHS and Betamax).

Finally, referring to an article on the past, present, and future of medical informatics [134] some of the aims mentioned there, relate to the question, where health-enabling and ambient assistive technologies will be in 25 years:

"Having in mind that today and in the near future (a) health has to be considered more and more as an integral and continuous part of life (not as health care within a limited time frame of a disease episode), [and] (b) medical informatics is addressing both, health professionals (plus their professional environment) and individuals/consumers (plus their social environment), ... future research fields ... might ... be ... 
1 seamless interactivity with automated data capture and storage for patient care, and beyond (from perception to high-level semantic concepts, related to human-human, machine-machine, as well as human-machine interaction; "beyond" in the meaning of not being restricted to certain disease episodes); ...

3 patient-centered data analysis and mining (with representations of patient data based on appropriate semantic concepts);

4 informatics diagnostics, where informatics tools (with corresponding methodology) form the major part of the diagnostic entity;

5 informatics therapeutics, where informatics tools (with corresponding methodology) form the major part of the therapeutic entity;

6 informatics capability-enhancing extensions, both mental and physical, to overcome (e.g. age-related) functional deficits (both external or internal to the human body, serving as implanted, immersive or external assistants, and providing a person with extended memories, senses, and connectivity); ...

9 identifying new disease patterns (e.g. using ubiquitously available patient information and medical/health knowledge, through, e.g., pervasively measured sensor data from individuals, and, e.g., by combining such data with molecular and clinical knowledge within social and living contexts); ...

11 elaborating concepts for appropriate health data bank architectures and for its organizations (allowing a range of local to global offerings for storing and maintaining personal health data);

12 elaborating concepts for patient-centered health information system architectures (within and in particular beyond health care institutions, allowing multiple usability of data) and its information management strategies (e.g. also considering data from ambient environments such as 'intelligent' buildings, and external, implanted or immersive body sensors);

with all these research fields being related to ... establishing and exploring the use of 'living labs““([134], p. 606-607).

\subsection{Which Aspects Should be Considered?}

On the question, which methodological and technological aspects as well as which political and societal aspects should be considered, authors again highlighted different aspects. As in section 6.1 the following statements are to some extent unstructured since we believed that this list is probably the best way of presenting the statements.

Health-enabling and ambient assistive technologies have, from a methodological viewpoint, the aim to improve health and health care, but we still have no evidence. Evaluation studies are needed [135]. These technologies need to be coupled to decision support. Methods to extract meaningful information to support decision making for different kinds of users are needed. From a technological viewpoint, we should consider a higher personalization of services, overcome issues of standardized data integration and interoperability (critical in regards to future decision support systems), as well as security and consent management.

Some of the most important aspects in the next 25 years will be ethical. Who owns the patient data? This is an old question in a new form. Already now patients request access to the data not only from their health records but also from implantable and wearable devices. But there is more. Who will own the value derived from this data? There is clearly a market for secondary use of patient data. More discussion on this topic can e.g. be found at [136].

The field of economics will contribute with theories and business models for two-or multi-sided markets.

In many respects the societal, political, and governance systems are major barriers to advances in this field. Even today there is a range of suitable assistive technologies that could be used extensively in patient management but are not because appropriate remuneration and health service delivery models need to be developed to accommodate the stakeholders involved in managing health through these new approaches. As newer sensing technologies become available and patients become more empowered by being able to monitor and manage their own health, the need for policy change will become even more apparent.
It can be expected that individual health, diseases, and medical costs during the course of a patient's life and lifespan will be predicted in much more detail unless there are limitations or regulations. The recent debate on the use of genomic information may also be of help to further discuss this context. Simultaneously, the threat of leaking private information has increased significantly. Not only the difficulty in obtaining health insurance, but the discrimination in marriage, employment, and career advancement could occur because of leaked data. We should develop methodologies for genome information storage, use, linking, and discarding the information.

With regard to societal aspects, it might be difficult to actually replace a physician, although we can easily imagine artificial intelligence systems' abilities to exceed a human physician's ability in the near future. We should consider societal aspects when, where, and how we can install such informatics systems into medical/health care services. Otherwise, it will be difficult to accept this advancement in medical/health care services, because clinicians do not want to be superseded in their position by artificial intelligence systems.

Technology that we describe as health-enabling technologies will merge in the everyday life of people. It will become natural for people to be observed by accompanying devices (nowadays smart phones, but that might be different in the future) and that these devices are embedded in a network of further devices owned by patients. Devices in this network will together be able to determine the status and trend of your health and wellbeing and persons will receive conscious and ambient advice on how to improve their health and wellness.

Patients should have full access to this information and should be able to share it with health care professionals. This either can be on demand, or pre-programmed in case of emergency.

The gathered information will be of great value for health care professionals. Like medical imaging or laboratory measurements today no serious health professional will ignore data gathered in a patient's everyday life. Likewise, the prescription of personalized drugs will be accompanied by the prescription of a 
computer-program that will not only remind patients of administration, but also adapt the dosage depending on a patient's current needs. Besides pharmaceutical drugs, computer based treatment will have proven its efficacy and will be established in medical routine.

It will be of importance to close the loop between research in health-enabling and ambient assistive technologies and the practice of health care and safe living. The need for studies on diagnostic relevance and therapeutic efficacy has already been mentioned several times. This will be combined with a market for products and services for such technologies (see e.g. [137]). Appropriate methodology for analysing such health-related, heterogeneous, multimodal, and multilocal data must be further developed. Aspects like using the home as additional 'setting' for health care (in addition to inpatient and outpatient settings like hospitals, nursing homes, or clinics) has to be considered, combined with further discussions on ethical, legal, and social implications, energy efficiency, and security aspects in the context of medical devices. Laws need to be adapted. In addition to patients and their care givers and health care professionals, other groups of professionals in particular in the context of living (e.g. for housing, mobility and shopping services) need to be also involved.

\section{Some Final Remarks}

It was our attempt to describe the state of the art of health-enabling and ambient assistive technologies from 1992 to today and how it has evolved across the last 25 years, as requested by the editors of this Yearbook. As mentioned in section 1.3, there are various limitations. The search strategy could be modified and the primary focus on research might have been chosen differently. Our systematic review centered on publications of the IMIA Yearbooks. Other sources might have been considered. Finally, as mentioned, we can not completely avoid subjectivity in our replies to key projects and visions as well as to lessons learned.

Are there any conclusions to be drawn? Certainly, the authors are convinced that health-enabling and ambient assistive technologies remain an important field for future health care and for (interdisciplinary) research in biomedicine and in the health sciences. And that a person's home is becoming an important additional 'institution' for health care.

Are there any recommendations and implications for future research? We tried to outline our views on this question in section 6. To put it in a nutshell: There was a clear progress on the use of technologies. However proof of diagnostic relevance and therapeutic efficacy is still needed.

The authors agree that there is still a long way to go and that it is a worthwhile and indeed necessary path to travel. We hope and look forward to reading a respective paper on the past, present, and future of health-enabling and ambient assistive technologies (independent of what they are called then, ...) in the 50th volume of the IMIA Yearbook.

\section{Conflicts of Interest Statement}

The authors do not see any conflicts of interest.

\section{Acknowledgements}

We cordially want to thank the editors of the Yearbook, Marie-Christine Jaulent, Christoph U. Lehmann, and Brigitte Séroussi, for their strong encouragement and support, Martina Hutter for her excellent editorial assistance, and the reviewers for their very helpful comments. Last, but not least, we explicitly want to acknowledge Chris Lehmann's careful proofreading. It also helped to sharpen our paper's contents and it therefore was actually much more than proofreading.

\section{References}

1. Email of Brigitte Seroussi (also on behalf of Marie-Christine Jaulent and Christoph U. Lehmann) from February 25, 2015, to the first author.

2. Demiris G. Smart homes and ambient assisted living in an aging society. New opportunities and challenges for biomedical informatics. Methods Inf Med 2008;47:56-7.

3. Koch S, Marschollek M, Wolf KH, Plischke M, Haux R. On health-enabling and ambient-assistive technologies. What has been achieved and where do we have to go? Methods Inf Med 2009;48:29-37.

4. Remagnino P, Foresti GL. Ambient intelligence: a new multidisciplinary paradigm. IEEE Trans Inf Technol Biomed 2005;9:1-6.

5. Bardram JE, Mihailidis A, Wan D, editors. Per- vasive computing in healthcare. Boca Raton, Fl.: CRC Press; 2007.

6. Saranummi N. IT applications for pervasive, personal, and personalized health. IEEE Trans Inf Technol Biomed 2008;12:1-4.

7. Bardram JE. Pervasive healthcare as a scientific discipline. Methods Inf Med 2008;47:178-85.

8. Martin S, Kelly G, Kernohan WG, McCreight B, Nugent C. Smart home technologies for health and social care support. Cochrane Database Syst Rev 2008:4:CD006412.

9. Bott OJ, Ammenwerth E, Brigl B, Knaup P, Lang E, Pilgram R, et al. The challenge of ubiquitous computing in health care: technology, concepts and solutions. Methods Inf Med 2005;44:473-9.

10. Arnrich B, Mayora O, Bardram J, Tröster G. Pervasive healthcare: paving the way for a pervasive, user-centered and preventive healthcare model. Methods Inf Med 2010;49:67-73.

11. Fardoun HM, Mashat AS, Lange B. New methodologies for patients rehabilitation. Methods Inf Med 2015;54:111-3.

12. Haux R, Howe J, Marschollek M, Plischke M, Wolf $\mathrm{KH}$. Health-enabling technologies for pervasive health care: on services and ICT architecture paradigms. Inform Health Soc Care 2008;33:77-89.

13. Mayora O, Lukowicz P, Marschollek M. Evolving pervasive health research into clinical practice. Methods Inf Med 2014;53:380-1.

14. Oberg PA, Togawa T, Spelman FA. Sensors in medicine and health care. Weinheim: WileyVCH; 2004.

15. Khusainov R, Azzi D, Achumba IE, Bersch SD. Real-time human ambulation, activity, and physiological monitoring: Taxonomy of issues, techniques, applications, challenges and limitations. Sensors 2013;13:12852-902.

16. Marschollek M, Rehwald A, Wolf KH, Gietzelt M, Nemitz G, 6. Autor et al. Sensors vs. experts - a performance comparison of sensor-based fall risk assessment vs. conventional assessment in a sample of geriatric patients. BMC Med Inform Decis Mak 2011;11:48.

17. Schwickert L, Becker C, Lindemann U, Maréchal C, Bourke A, Chiari L et al.; FARSEEING Consortium and the FARSEEING Meta Database Consensus Group. Fall detection with body-worn sensors: a systematic review. Z Gerontol Geriatr 2013;46:706-19.

18. Chan M, Estève D, Escriba C, Campo E. A review of smart homes - present state and future challenges. Comput Methods Programs Biomed 2008;91:55-81.

19. Ludwig W, Wolf KH, Duwenkamp C, Gusew N, Hellrung N, Marschollek M, et al. Health-enabling technologies for the elderly - an overview of services based on a literature review. Comput Methods Programs Biomed 2012;106:70-8.

20. Winter A, Haux R, Ammenwerth E, Brigl B, Hellrung N, Jahn F. Health information systems - architectures and strategies. London: Springer; 2011.

22. Ludwig W, Wolf KH, Duwenkamp C, Gusew N, Hellrung N, Marschollek M, et al. Health information systems for home telehealth services - a nomenclature for sensor-enhanced transinstitutional information system architectures. Inform Health Soc Care 2010;35:211-25. 
21. Marschollek M. Recent progress in sensor-enhanced health information systems - slowly but sustainably. Inform Health Soc Care 2009;34:225-30.

23. Knaup P, Schöpe L. Using data from ambient assisted living and smart homes in electronic health records. Methods Inf Med 2014;53:149-51.

24. Haux R. Medical Informatics: past, present, future. Int J Med Inform 2010;49:599-610.

25. World Health Organization. eHealth series. http:// www.who.int/goe/publications/en. Last access: November 28, 2015.

26. Black AD, Car J, Pagliari C, Anandan C, Cresswell $\mathrm{K}$, author et al. The Impact of eHealth on the Quality and Safety of Health Care: A Systematic Overview. PLoS Med 2011;8:e1000387.

27. Al-Shorbaji N. The World Health Assembly resolutions on eHealth: eHealth in support of universal health coverage. Methods Inf Med 2013;52:463-6.

28. Li Y, Owen T, Thimbleby H, Sun N, Rau PL. A design to empower patients in long term wellbeing monitoring and chronic disease management in mHealth. Stud Health Technol Inform 2013;194:82-7.

29. Ekeland AG, Bowes A, Flottorp S. Effectiveness of telemedicine: a systematic review of reviews. Int J Med Inform 2010;79:736-71.

30. Pecina JL, Hanson GJ, Van Houten H, Takahashi PY. Impact of telemonitoring on older adults health-related quality of life: the Tele-ERA study. Qual Life Res 2013;22:2315-21.

31. Inglis SC, Clark RA, McAlister FA, Stewart S, Cleland JG. Which components of heart failure programmes are effective? A systematic review and meta-analysis of the outcomes of structured telephone support or telemonitoring as the primary component of chronic heart failure management in 8323 patients: Abridged Cochrane Review. Eur J Heart Fail 2011;13:1028-40.

32. Chaudhry SI, Mattera JA, Curtis JP, Spertus JA, Herrin J, Lin Z, et al. Telemonitoring in Patients with Heart Failure. N Engl J Med 2010;363:2301-9.

33. Liberati A, Altman DG, Tetzlaff J, Mulrow C, Gøtzsche PC, Ioannidis JP et al. The PRISMA statement for reporting systematic reviews and meta-analyses of studies that evaluate health care interventions: explanation and elaboration. PLoS Med 2009:6:e1000100.

34. Haux R, Knaup P, Bauer AW, Herzog W, Reinhardt $\mathrm{E}$, Überla $\mathrm{K}$, et al. Information processing in healthcare at the start of the third Millennium: potential and limitations. Yearb Med Inform 2002:187-93.

35. Haux R, Knaup P, Bauer AW, Herzog W, Reinhardt $\mathrm{E}$, Überla $\mathrm{K}$, et al. Information processing in healthcare at the start of the third Millennium: potential and limitations. Methods Inf Med 2001:40:156-62.

36. Lukowicz P, Kirstein T, Tröster G. Wearable systems for health care applications. Yearb Med Inform 2005:236-42

37. Lukowicz P, Kirstein T, Tröster G. Wearable systems for health care applications. Methods Inf Med 2004:43:232-8.

38. Maiolo C, Mohamed EI, Fiorani CM, De Lorenzo A. Home telemonitoring for patients with severe respiratory illness: the Italian experience. Yearb Med Inform 2005:243-7.
39. Maiolo C, Mohamed EI, Fiorani CM, De Lorenzo A. Home telemonitoring for patients with severe respiratory illness: the Italian experience. J Telemed Telecare 2003;9:67-71.

40. Schek H-J. Ubiquitous computing and pervasive health care. Yearb Med Inform 2005:1-3.

41. Tröster G. The agenda of wearable healthcare. Yearb Med Inform 2005:125-38.

42. Anliker U, Ward JA, Lukowicz P, Tröster G, Dolveck F, Baer M, et al. AMON: a wearable multiparameter medical monitoring and alert system. Yearb Med Inform 2006:55 (summary).

43. Anliker U, Ward JA, Lukowicz P, Tröster G, Dolveck F, Baer M, et al. AMON: a wearable multiparameter medical monitoring and alert system. IEEE Trans Inf Technol Biomed 2004;8:415-27.

44. Cappuccio FP, Kerry SM, Forbes L, Donald A. Blood pressure control by home monitoring: meta-analysis of randomised trials. Yearb Med Inform 2006:18 (summary).

45. Cappuccio FP, Kerry SM, Forbes L, Donald A. Blood pressure control by home monitoring: meta-analysis of randomised trials. BMJ 2004;329(7458):145. Erratum in: BMJ 2004;329(7464):499.

46. Kuhn KA, Wurst SH, Bott OJ, Giuse DA. Expanding the scope of health information systems. Challenges and developments. Yearb Med Inform 2006:43-52.

47. Stefanov DH, Bien Z, Bang WC. The smart house for older persons and persons with physical disabilities: structure, technology arrangements, and perspectives. Yearb Med Inform 2006:56 (summary).

48. Stefanov DH, Bien Z, Bang WC. The smart house for older persons and persons with physical disabilities: structure, technology arrangements, and perspectives. IEEE Trans Neural Syst Rehabil Eng 2004;12:228-50.

49. Istrate D, Castelli E, Vacher M, Besacier L, Serignat JF. Information extraction from sound for medical telemonitoring. Yearb Med Inform 2007:72 (summary)

50. Istrate D, Castelli E, Vacher M, Besacier L, Serignat JF. Information extraction from sound for medical telemonitoring. IEEE Trans Inf Technol Biomed 2006;10:264-74.

51. Konstantas D. An overview of wearable and implantable medical sensors. Yearb Med Inform 2007:66-9.

52. Pärkkä J, Ermes M, Korpipää P, Mäntyjärvi J, Peltola J, Korhonen I. Activity classification using realistic data from wearable sensors. Yearb Med Inform 2007:72-3 (summary).

53. Pärkkä J, Ermes M, Korpipää P, Mäntyjärvi J, Peltola J, Korhonen I. Activity classification using realistic data from wearable sensors. IEEE Trans Inf Technol Biomed 2006;10:119-28.

54. Shea S, Weinstock RS, Starren J, Teresi J, Palmas W, Field L, et al. A randomized trial comparing telemedicine case management with usual care in older, ethnically diverse, medically underserved patients with diabetes mellitus. Yearb Med Inform 2007:33 (summary).

55. Shea S, Weinstock RS, Starren J, Teresi J, Palmas $\mathrm{W}$, Field L, et al. A randomized trial comparing telemedicine case management with usual care in older, ethnically diverse, medically underserved patients with diabetes mellitus. J Am Med Inform Assoc 2006;13:40-51.

56. Demiris G, Hensel BK. Technologies for an aging society: a systematic review of "smart home" applications. Yearb Med Inform 2008:33-40.

57. Logan AG, McIsaac WJ, Tisler A, Irvine MJ, Saunders A, Dunai A, et al. Mobile phone-based remote patient monitoring system for management of hypertension in diabetic patients. Yearb Med Inform 2008: 31 (summary).

58. Logan AG, McIsaac WJ, Tisler A, Irvine MJ, Saunders A, Dunai Aet al. Mobile phone-based remote patient monitoring system for management of hypertension in diabetic patients. Am J Hypertens 2007;20:942-8

59. Zheng JW, Zhang ZB, Wu TH, Zhang Y. A wearable mobihealth care system supporting real-time diagnosis and alarm. Yearb Med Inform 200866 (summary)

60. Zheng JW, Zhang ZB, Wu TH, Zhang Y. A wearable mobihealth care system supporting real-time diagnosis and alarm. Med Biol Eng Comput 2007; $45: 877-85$.

61. O'Shea SI, Arcasoy MO, Samsa G, Cummings SE, Thames EH, Surwit RS, et al. Direct-to-patient expert system and home INR monitoring improves control of oral anticoagulation. Yearb Med Inform 2010:46 (summary).

62. O'Shea SI, Arcasoy MO, Samsa G, Cummings SE, Thames EH, Surwit RS, et al. Direct-to-patient expert system and home INR monitoring improves control of oral anticoagulation. J Thromb Thrombolysis 2008;26:14-21.

63. Demiris G, Thompson H. Smart homes and ambient assisted living applications: from data to knowledge-empowering or overwhelming older adults? Yearb Med Inform 2011:51-7.

64. Maeder AJ, Gogia SB, Hartvigsen G. Next generation telehealth. Yearb Med Inform 2011:15-20.

65. Stroetmann V, Thiel R, Stroetmann KA, Wilson P, Romao M, Strubin M. Understanding the role of device level interoperability in promoting health - lessons learned from the SmartPersonalHealth Project. Yearb Med Inform 2011:87-91.

66. Akay YM, Akay M, Welkowitz W, Semmlow JL, Kostis JB. Noninvasive acoustical detection of coronary artery disease: a comparative study of signal processing methods. IEEE Trans Biomed Eng 1993;40:571-8.

67. Ishijima M. Cardiopulmonary monitoring by textile electrodes without subject-awareness of being monitored. Med Biol Eng Comput 1997;35:685-90.

68. Doughty K, Lewis R, McIntosh A. The design of a practical and reliable fall detector for community and institutional telecare. J Telemed Telecare 2000; 6 Suppl 1:S150-4.

69. Schwarzer G, Vach W, Schumacher M. On the misuses of artificial neural networks for prognostic and diagnostic classification in oncology. Stat Med 2000;19:541-61.

70. Budinger TF. Biomonitoring with wireless communications. Annu Rev Biomed Eng 2003;5:383-412.

71. Heckerling PS, Gerber BS, Tape TG, Wigton RS. Entering the black box of neural networks. Methods Inf Med 2003;42:287-96.

72. Lymberis A, Olsson S. Intelligent biomedical clothing for personal health and disease manage- 
ment: state of the art and future vision. Telemed J E Health 2003 Winter;9:379-86.

73. Winters JM, Wang Y, Winters JM. Wearable sensors and telerehabilitation. IEEE Eng Med Biol Mag 2003;22:56-65.

74. Saranummi N. IT applications for pervasive, personal, and personalized health. IEEE Trans Inf Technol Biomed 2008;12:1-4.

75. Celler BG, Earnshaw W, Ilsar ED, Betbeder-Matibet L, Harris MF, Clark R, et al. Remote monitoring of health status of the elderly at home. A multidisciplinary project on aging at the University of New South Wales. Int J Biomed Comput 1995;40:147-55.

76. Intille SS. Designing a home of the future. IEEE Pervasive Computing 2002 (April-June):80-6.

77. Intille SS. The goal: smart people, not smart homes. In: Nugent C, Augusto JC, editors. Smart Homes and Beyond, Amsterdam: IOS; 2006.

78. Gómez EJ, Hernando Pérez ME, Vering T, Rigla Cros M, Bott O, et al. The INCA system: a further step towards a telemedical artificial pancreas. IEEE Trans Inf Technol Biomed 2008;12:470-9.

79. Darkins A, Ryan P, Kobb R, Foster L, Edmonson E, Wakefield B, et al. Care Coordination/Home Telehealth: the systematic implementation of health informatics, home telehealth, and disease management to support the care of veteran patients with chronic conditions. Telemed J E Health 2008;14:1118-26.

80. Project HealthDesign. http://www.projecthealthdesign.org/projects. Last access: November 28, 2015

81. Haux R, Hein A, Eichelberg M, Appell JE, Appelrath HJ, Bartsch C, et al. The Lower Saxony research network design of environments for ageing: towards interdisciplinary research on information and communication technologies in ageing societies. Inform Health Soc Care 2010;35:92-103.

82. http://www.fit4age.org. Last access: November 28, 2015.

83. http://www.oasis-project.eu. Last access: November 28,2015

84. Healy JC. The WHO eHealth Resolution. eHealth for All by 2015? Methods Inf Med 2007;46:2-3.

85. Al-Shorbaji N. The World Health Assembly Resolutions on eHealth: eHealth in support of universal health coverage. Methods Inf Med 2013;52:463-6.

86. Demiris G, Thompson HJ. Mobilizing Older Adults: Harnessing the Potential of Smart Home Technologies. Contribution of the IMIA Working Group on Smart Homes and Ambient Assisted Living. Yearb Med Inform 2012:94-9.

87. Gogia SB, Maeder A, Meher S, Mars M, Hartvigsen $\mathrm{G}$, Kuthiala A. Using Personal Handheld Computing Devices for Personalizing Healthcare. Yearb Med Inform 2012:74-8

88. Khushaba RN, Kodagoda S, Lal S, Dissanayake G. Driver drowsiness classification using fuzzy wavelet-packet-based feature-extraction algorithm. Yearb Med Inform 2012:102 (summary).

89. Khushaba RN, Kodagoda S, Lal S, Dissanayake G. Driver drowsiness classification using fuzzy wavelet-packet-based feature-extraction algorithm. IEEE Trans Biomed Eng 2011;58:121-31.

90. Koch S, Vimarlund V. Critical advances in bridging personal health informatics and clinical informatics. Yearb Med Inform 2012:48-55.

91. Leong TY. Toward patient-centered, personalized and personal decision support and knowledge management: a survey. Yearb Med Inform 2012:104-12.

92. Paton C, Hansen M, Fernandez-Luque L, Lau AY. Self-Tracking, Social Media and Personal Health Records for Patient Empowered Self-Care. Yearb Med Inform 2012:16-24.

93. Wac K. Smartphone as a personal, pervasive health informatics services platform: literature review. Yearb Med Inform 2012:83-93.

94. Abbott PA, Liu Y. A scoping review of telehealth. Yearb Med Inform 2013:51-8.

95. Jeong S, Youn CH, Shim EB, Kim M, Cho YM, Peng L. An integrated healthcare system for personalized chronic disease care in home-hospital environments. Yearb Med Inform 2013:65-6 (summary).

96. Jeong S, Youn CH, Shim EB, Kim M, Cho YM, Peng L. An integrated healthcare system for personalized chronic disease care in home-hospital environments. IEEE Trans Inf Technol Biomed 2012;16:572-85

97. Klasnja P, Pratt W. Healthcare in the pocket: mapping the space of mobile-phone health interventions. Yearb Med Inform 2013:66 (summary).

98. Klasnja P, Pratt W. Healthcare in the pocket: mapping the space of mobile-phone health interventions. J Biomed Inform 2012:45:184-98.

99. McCoy AB, Wright A, Eysenbach G, Malin BA, Patterson ES, Xu H, et al. State of the art in clinical informatics: evidence and examples. Yearb Med Inform 2013:13-9.

100. Capozzi D, Lanzola G. A generic telemedicine infrastructure for monitoring an artificial pancreas trial. Yearb Med Inform 2014:56-7 (summary).

101. Capozzi D, Lanzola G. A generic telemedicine infrastructure for monitoring an artificial pancreas trial. Comput Methods Programs Biomed 2013;110:343-53.

102. Carrault G, Mabo P. Are electronic cardiac devices still evolving? Yearb Med Inform 2014:128-34

103. Hansen MM, Miron-Shatz T, Lau AY, Paton C. Big Data in Science and Healthcare: A Review of Recent Literature and Perspectives. Yearb Med Inform 2014:21-6.

104. Luna D, Mayan JC, García MJ, Almerares AA, Househ M. Challenges and potential solutions for big data implementations in developing countries. Yearb Med Inform 2014: 36-41.

105. Redmond SJ, Lovell NH, Yang GZ, Horsch A, Lukowicz P, Murrugarra L, et al. What does big data mean for wearable sensor systems? Yearb Med Inform 2014:135-42.

106. Safran C. Reuse of clinical data. Yearb Med Inform 2014:52-4.

107. Vimarlund V, Wass S. Big data, smart homes and ambient assisted living. Yearb Med Inform 2014:143-9.

108. PewResearchCenter. http://www.pewinternet. org/2013/01/28/tracking-for-health/. Last access: November 28, 2015.

109. http://quantifiedself.com/symposium/Symposium-2014/QSPublicHealth2014_Report.pdf. Last access: November 28, 2015.

110. Steventon A, Bardsley M, Billings J, Dixon J, Doll H, 6. author et al; Whole System Demonstrator Evaluation Team. Effect of telehealth on use of secondary care and mortality: findings from the Whole System Demonstrator cluster randomised trial. BMJ 2012 Jun 21;344:e3874.

111. Marschollek M, Becker M, Bauer J, Bente P, Dasenbrock L, Elbers K, et al. Multimodal activity monitoring for home rehabilitation of geriatric fracture patients - feasibility and acceptance of sensor systems in the GAL-NATARS- Study. Inform Health Soc Care 2014;39:262-71.

112. Haux R, Hein A, Kolb G, Künemund H, Eichelberg M, Appell JE, et al; Lower Saxony Research Network GAL. Information and communication technologies for promoting and sustaining quality of life, health and self-sufficiency in ageing societies - outcomes of the Lower Saxony Research Network Design of Environments for Ageing (GAL). Inform Health Soc Care 2014;39:166-87.

113. German National Cohort (GNC) Consortium. The German National Cohort: aims, study design and organization. Eur J Epidemiol 2014;29:371-82.

114. UK Biobank, http://www.ukbiobank.ac.uk. Last access: November 28, 2015.

115. Building Automation by a Scalable \& Intelligent System (BASIS) project. https://www.ida.ing. tu-bs.de/en/research/projects/basis/. Last access: November 28, 2015.

116. Ahmed A, Inoue S, Kai E, Nakashima N, Nohara Y. Portable Health Clinic: A pervasive way to serve the unreached community for preventive healthcare. In: Streitz N, Stephanidis C, editors. DAPI/HCII 2013, 265-74. Heidelberg: Springer; 2013.

117. Nakashima N, Hiramatsu T, Ghosh PP, Islam R, Kobayashi K, Inoguchi T. Evaluation of "Portable Health Clinic" with BAN standard for $10 \mathrm{~K}$ subjects in Bangladesh. Conf Proc IEEE Eng Med Biol Soc 2013;2013:1672-5.

118. Nakashima N, Nohara Y, Ahamed A, Kuroda M, Inoue S, Ghosh PP, et al. An affordable, usable and sustainable preventive healthcare system for unreached people in Bangladesh. Stud Health Technol Inform 2013;192:1051

119. Shany T, Wang K, Liu Y, Lovell NH, Redmond SJ. Are we stumbling in our quest to find the best predictor? Over-optimism in sensor-based models for predicting falls in older adults, Healthcare Technology Letters 2015;2(4):79-88.

120. Valenza G, Citi L, Gentili C, Lanatá A, Scilingo EP, Barbieri R. Point-process nonlinear autonomic assessment of depressive states in bipolar patients. Methods Inf Med 2014;53:296-302.

121. Maier C, Wenz H, Dickhaus H. Robust detection of sleep apnea from Holter ECGs. Joint assessment of modulations in QRS amplitude and respiratory myogram interference. Methods Inf Med 2014;53:303-7.

122. Migliorini M, Kortelainen JM, Pärkkä J, Tenhunen M, Himanen SL, Bianchi AM. Monitoring nocturnal heart rate with bed sensor. Methods Inf Med 2014;53:308-13.

123. Wang C, Lu W, Narayanan MR, Redmond SJ, Lovell NH. Low-power technologies for wearable telecare and telehealth systems: A review. Biomedical Engineering Letters 2015;5:1-9.

124. Shany T, Redmond SJ, Narayanan M, Lovell NH Sensors-based wearable systems for monitoring of human movement and falls, IEEE Sensors 
Journal 2012;12:658-70.

125. Zheng YL, Ding XR, Poon CCY, Lo BPL, Zhang $\mathrm{H}$, Zhou XL, et al. Unobtrusive sensing and wearable devices for health informatics. IEEE Trans Biomed Eng 2014;61:1538-54.

126. Gietzelt M, von Bargen T, Kohlmann M, Marschollek M, Schwartze J, Song B, et al. Home-centered health-enabling technologies and regional health information systems. An integration approach based on international standards. Methods Inf Med 2014;53:160-6.

127. Hafen E, Kossmann D, Brand A. Health data cooperatives - citizen empowerment. Methods Inf Med 2014;53:82-6.

128. Nitzsche T, Thiele S, Häber A, Winter A. Communication architecture for AAL. Supporting patient care by health care providers in AAL-enhanced living quarters. Methods Inf Med 201453:167-72.

129. Plischke M, Wagner M, Haarbrandt B, Rochon M, Schwartze J, Tute E, et al. The lower saxony bank of health. rationale, principles, services, organization and architectural framework. Methods Inf Med 2014;53:73-81.

130. Haux R, Ammenwerth E, Herzog W, Knaup P. Health care in the information society. A prognosis for the year 2013. Int J Med Inform 2002;66:3-21

131. Haux R, Ammenwerth E, Knaup P. Reflections on "health care in the information society -a prognosis for the year 2013'. J Med Syst 2014;38:72.

132. Knaup P, Ammenwerth E, Dujat C, Grant A, Hasman A, Hein A, et al. Assessing the prognoses on Health care in the information society 2013 -thirteen years after. J Med Syst 2014;38:73.

133. De Chazal P, Fox N, O'Hare EMER, Heneghan
C, Zaffaroni A, Boyle P, et al. Sleep/wake measurement using a non-contact biomotion sensor J Sleep Res 2011;20:356-66.

134. Haux R. Medical informatics: past, present, future. Int J Med Inform 2010;79:599-610.

135. Ammenwerth E. Evidence-based Health Informatics: How Do We Know What We Know? Methods Inf Med 2015;54:298-307.

136. e-patients.net. http://e-patients.net/archives/ 2012/11/when-is-patient-data-not-patient-datawhen-a-patient-wants-his-or-her-icd-data.html. Last access: November 28, 2015.

137. ITECH. http://www.itech-project.eu. Last access: November 22, 2015.

\section{Correspondence to:}

Prof. Dr. Reinhold Haux, Dr. Klaus-Hendrik Wolf

Peter L. Reichertz Institute for Medical Informatics

University of Braunschweig - Institute of Technology and Hannover Medical School

Muehlenpfordtstr. 23

38106 Braunschweig

Germany

reinhold.haux@plri.de,klaus-hendrik@wolf@plri.de

www.plri.de

Prof. Dr. Sabine Koch

Department of Learning, Informatics, Management and Ethics

Health Informatics Centre

Karolinska Institutet

Tomtebodavägen 18a

17177 Stockholm

Sweden

sabine.koch@ki.se

ki.se/en/lime/hic-health-informatics-centre
Prof. Dr. Nigel H. Lovell

Graduate School of Biomedical Engineering

UNSW

Sydney NSW 2052

Australia

n.lovell@unsw.edu.au

www.gsbme.unsw.edu.au

Prof. Dr. Dr. Michael Marschollek

Peter L. Reichertz Institute for Medical Informatics

University of Braunschweig - Institute of Technology and

Hannover Medical School

Carl-Neuberg-Strasse 1

30625 Hannover

Germany

michael.marschollek@plri.de

www.plri.de

Prof. Dr. Dr. Naoki Nakashima

Medical Information Center

Kyushu University Hospital

3-1-1 Maidashi, Higashi-ku

Fukuoka 812-8582

Japan

nnaoki@info.med.kyushu-u.ac.jp

www.temdec.med.kyushu-u.ac.jp 